\title{
Development of Tractor Operated Farm Yard Manure Spreader
}

\author{
Lalit Savaliya*, T. D. Mehta, Ravi Kathiria and Ravikumar Hirpara \\ Department of Farm Machinery and Power Engineering, CAET, Junagadh Agricultural \\ University, Junagadh, India \\ *Corresponding author
}

\section{A B S T R A C T}

Keywords

Tractor operated, Farm Yard Manure, Spreading, Spreading blades

\section{Article Info}

\section{Accepted:}

07 January 2021

Available Online:

10 February 2021
FYM is applied by bullock cart or tractor trailer making the heaps in field and then spreading manually in randomized way which results in unevenness of the application. This operation requires labors and also uniformity is not maintained in this operation. To facilitate the efficient crop utilization of manure, spreading of it more uniformly across the field is advantageous. It is necessary that the quantified the rate of application during the operation and spread uniformly, covering the whole surface of the field. Therefore unit like tractor operated Farm Yard Manure spreader is desirable. In this project such a device will be developed which monitors the rate of FYM application either in the furrow or to make uniform spreading of it. Testing was earned in field for both manual and mechanical spreading operation. The speed of operation was $1.8 \mathrm{~km} / \mathrm{h}$ for spreading operation. The fuel consumption observed a $2.11 \mathrm{l} / \mathrm{h}$ for spreading operation. The performance of FYM spreader was determined, by different parameters. The FYM application rate was 8750 $\mathrm{kg} / \mathrm{ha}$.

\section{Introduction}

Agriculture has been the backbone of Indian economic progress and development. The role of agriculture including animal husbandry, dairy and fisheries account for some $14.5 \%$ of the country GDP and about $52 \%$ of work force depends directly or indirectly on agriculture for its livelihood and support (Anon., 2019).

Mechanically FYM is applied by tractor trolley which consist of three to four outlets, the tractor trolley is completely filled with FYM and tractor is allow to run on field. As trolley has lifted the material in it comes out from the outlets. But there is drudgery in this method of application because two or three persons are required to push the material towards the openings, it is a laborious job. This method also does not get that much uniformity as required but labour requirement is less than manual method. It requires skilled labour for operation.

Though the application of manure has become mechanized in other countries like other field operations, but in India, the application of FYM is done manually. First, the loaded trolley or bullock cart with FYM is stopped at average distance of $5 \mathrm{~m}$ and unloads 150 to $200 \mathrm{~kg}$ of FYM in the form of a heap. Later, 
these heaps are spread around manually with spades.

This operation requires labours who get tired at the end of the day and also uniformity is not maintained in this operation. Only advantage in manual method is that it does not require skilled labour to spread it.

It can be quantified the rate of application during the operation and spread uniformly, covering the whole surface of the field. Therefore tractor operated Farm Yard Manure Spreader type unit is desirable. In this study such a device was planned to be developed which spread the FYM heaps either in the furrow or on surface. This device will be simple and low in cost.

\section{Materials and Methods}

This chapter deals with the methods adopted in development of tractor operated farm yard manure spreader and the experimental methodology used to evaluate the machine for its performance.

\section{Physical properties of FYM}

After development of FYM spreader initial trials were conducted to check the working of the machine with the wet FYM. It was observed that the wet FYM does not move freely from the equipment. The drying of FYM improves the physical properties and encourages the machine performance as the physical properties of the FYM influence the machine performance. The important physical properties are moisture content, bulk density, angle of repose, coefficient of friction of FYM.

\section{Centrifugal spreading concept}

Over $90 \%$ of the fertilizers are distributed using spinning disc spreaders. The popularity of spinning disc spreaders lies in their relatively low cost and relatively high accuracy. Furthermore, they allow a high working width (more than $36 \mathrm{~m}$ nowadays) and easy maintenance.

Depending on the scale of the application, a centrifugal spreader contains a spreading disc. Since the bulk density of FYM is roughly 325 $\mathrm{kg} / \mathrm{m}^{3}$. Directly under the gear box, a spinning disc is mounted, which is driven by the tractor transmission (mechanically). The particles of FYM heap was thrown in the field, forming the spread pattern. Usually, 4 blades rotating in one direction was used to improve the symmetry of the spread pattern. The spinning disc type is also applied for smaller applications or domestic use. Usually, here, the working width is a few meters and the disc is driven by PTO power.

\section{General considerations}

Following general considerations will be taken into note

1) It should be simple in fabrication and easy to manufacture using locally available material and less cost of construction.

2) All parts should be easily assembled and dismantled for inspection and repair.

\section{Calculation of shaft diameter}

The diameter of the shaft was determined by using following equation,

$$
\mathbf{T}=\left(\frac{\pi}{16}\right)^{3}
$$

Where,

$\mathrm{T}=$ Torque, $\mathrm{N}-\mathrm{m}$

$=$ Torsional shear stress, $60 \mathrm{~N} / \mathrm{mm}^{2}$

$\mathrm{P}=$ Power, $\mathrm{kW}(28.952 \mathrm{~kW})$

$\mathrm{d}=$ Diameter of solid shaft, $\mathrm{mm}$ 
Now for determination of required power,

$\mathbf{P}=\frac{2 \pi \mathrm{NT}}{60}$

Where,

$\mathrm{N}=$ Speed, rev/min (180)

Putting the value in eqn. (3.10)

$$
\mathrm{T}=\frac{28.952 \times 60 \times 1000}{2 \times 3.14 \times 180}=657.91 \times 10
$$

Now putting the value of $\mathrm{T}$ in eqn. using = $60 \mathrm{MPa}=60 \mathrm{~N} / \mathrm{mm}^{2}$ for mild steel.

The diameter of shaft comes out as,

$\mathrm{d}^{3}=\quad \frac{610.91 \times 1}{3.14}=55363.91 \mathrm{~s}$

$\mathrm{d}=42.01 \mathrm{~mm} \quad 42 \mathrm{~mm}$

The shaft was designed for $42.5 \mathrm{~mm}$ diameter of $1810 \mathrm{~mm}$ length.

Average PTO power of $45 \mathrm{hp}$ tractor was 540 rpm. The gear box has reduction gear which reduces the rpm up to third level. The ratio of PTO to gear box was 1:3.

\section{Thickness of blade}

The thickness of blade calculated by the formula

$$
\mathrm{M} / \mathrm{I}=\mathrm{F} / \mathrm{Y}
$$

Where, $\mathrm{M}=$ Bending moment acting on blade section, kg.cm

$\mathrm{I}=$ Second Moment of area of cross section about the neutral axis, $\mathrm{cm}^{4}$

$\mathrm{F}=$ Bending stress, $\mathrm{kg} / \mathrm{cm}^{2}$

$\mathrm{Y}=$ Distance from neutral axis to the extreme edge, $\mathrm{cm}$
As,

$\mathrm{M}=$ Force $\times$ Distance

$=300 \times 14$

$=4200 \mathrm{~kg} . \mathrm{cm}$

$\mathrm{F}=$ Allowable bending stress $=900 \mathrm{~kg} / \mathrm{cm}^{2}$

$\mathrm{Y}=9.5 / 2=4.75 \mathrm{~cm}$

$\mathrm{I}=\mathrm{tb}^{3} / 12=\mathrm{t}(14)^{3} / 12=228.66 \mathrm{t}$

Where,

$\mathrm{t}=$ Thickness of blade, $\mathrm{cm}$

$\mathrm{b}=$ Maximum width of blade, $\mathrm{cm}$

By putting this value in main equation

$\mathrm{t}=4200 \times 4.75 / 228.66 \times 900$

$\mathrm{t}=0.096 \mathrm{~cm}$

$\mathrm{t}=0.96 \mathrm{~mm}$

Considering, the factor of safety and availability of material, the thickness of blade was kept $3.5 \mathrm{~mm}$.

\section{Functional requirements}

Following functional requirements were considered during development of new unit.

1) The power requirement should be within the capacity of available tractor i.e. $45 \mathrm{hp}$ to $50 \mathrm{hp}$ range. The hydraulic lifting capacity of this ranged tractor is about 250 to $350 \mathrm{~kg}$.

2) The material mixing property should meet the easy conveying.

3) The RPM of the output shaft should be reduced through gearbox for easy spreading.

4) It should accommodate the material as per its designed capacity.

5) The implement should have hydraulic 
control system for mechanism to lift, hold and lower the implement.

\section{Details of developed tractor operated farm yard manure spreader}

It consists of frame, three point hitch, universal joint, support frames, main shaft, gear box, gear box adjustment, spreader assembly and spreader cutting blades. In spreading unit, spreader blades assembly fitted below the gear box with supporting pipe. It consists four blades each fitted four L type blades. The working blades cut the portion of farm yard manure and throws in circular direction.

\section{Performance parameters}

\section{Theoretical field capacity}

It is the rate of area covered without loss of time. It was calculated by using following formula.

Theoretical field capacity $\left(\frac{\mathrm{ha}}{\mathrm{h}}\right)=\frac{\text { Width of coverage }(\mathrm{m}) \times \text { Speed }\left(\frac{\mathrm{km}}{\mathrm{h}}\right)}{10}$

\section{Effective field capacity}

It is the actual rate of work which includes the time lost in turning at the end of heaps line. It was calculated by using following formula.

Effective field capacity $\left(\frac{\text { ha }}{\mathrm{h}}\right)=\frac{\text { Width of coverage }(\mathrm{m}) \times \text { Length of strip }(\mathrm{m})}{\text { Time taken }(\mathrm{h}) \times 10,000}$

\section{Field efficiency}

Field efficiency is defined as the percentage of time the machine operates at its full rated speed and width while in the field. It was calculated by using following formula.

Field efficiency $(\%)=\frac{\text { Effective field capacity }}{\text { Theoretical field capacity }} \times 100$

\section{Uniformity of spreaded FYM}

The uniformity of the spreading of farm yard manure machine was determined by methods of collecting sample. In first total area covered with farm yard manure after operation was determined and compare with left area.

In that process to find out the highest reach and best spreading lime powder total of $40 \mathrm{~kg}$ used to measure the distribution and uniformity of FYM spreader. The lime powder was dropped and mixed in heaps so that after spreading manually and mechanically comparison made easy.

\section{Fuel consumption}

The fuel consumption of tractor operated farm yard manure spreader was measured as per the standard prescribed method. The auxiliary tank was attached in between fuel tank and engine inlet manifold.

The time of operation by tractor and fuel consumed were recorded. Fuel consumption of tractor was determined by dividing the fuel consumed to the time of operation.

\section{Evaluation of economics}

\section{Time}

The total time required for operation of spreader for spreading includes time required for turning, repair and adjustment. The time required for operation will be measured with the help of stop watch.

\section{Energy}

The working hours of human labour will be determined in each operation and pooled to get total human energy. The mechanical energy used on the selected farms includes 
tractor and diesel engines. The mechanical energy will be computed on the basis of total fuel consumption $(1 / h)$ in different operation. The energy consumed will be calculated using conversion factors and it will be expressed in $\mathrm{MJ} / \mathrm{ha}$.

\section{Cost economics}

The cost of operation of the machine in terms of 'per hectare' and 'per hour' was determined. The total cost of operation per hour of the machine was computed. It was determined as the sum of the fixed and variable cost.

Fixed cost includes depreciation, interest on capital, insurance, taxes and housing. The cost of fuel, lubrication, repair and maintenance and operator were added to the variable cost. It was converted into area basis by multiplying it with the effective field capacity of the machine and expressed in rupees per hectare.

\section{Results and Discussion}

Performance of the developed machine was evaluated this study (Fig. 1-3, Table 1 and 2).

\section{Performance parameter}

\section{Theoretical field capacity}

Theoretical field capacity for spreading operation was $0.75 \mathrm{ha} / \mathrm{h}$ and for manually spreading varies from 0.052 to $0.068 \mathrm{ha} / \mathrm{h}$.

\section{Effective field capacity}

The effective field capacity for spreading was $0.58 \mathrm{ha} / \mathrm{h}$ and for manually spreading varies from 0.042 to $0.049 \mathrm{ha} / \mathrm{h}$.

\section{Field efficiency}

The field efficiency of spreader for spreading was $77.33 \%$ also manually spreading was $68.42 \%$.

Table.1 Cost parameters of tractor operated farm yard manure spreader

\begin{tabular}{|l|l|l|}
\hline Sr. No. & Parameters & Values \\
\hline $\mathbf{1}$ & Capital cost of tractor operated farm yard manure spreader & $\square 43,000$ \\
\hline $\mathbf{2}$ & Cost for spreading operation & $\square 487.87 / \mathrm{h}$ \\
\hline $\mathbf{3}$ & Custom hiring charge & $\square 609.75 / \mathrm{h}$ \\
\hline $\mathbf{4}$ & Payback period & 1.17 year \\
\hline $\mathbf{5}$ & Benefit Cost ratio & 8.50 \\
\hline $\mathbf{6}$ & Total Cost for spreading operation & $\square 650.40 / \mathrm{ha}$ \\
\hline
\end{tabular}

Table.2 Cost parameter of manually spreading method

\begin{tabular}{|l|l|l|}
\hline Sr. no. & Parameter & Value \\
\hline $\mathbf{1}$ & Total Time required for spreading of FYM, man-h/ha & 15.44 \\
\hline $\mathbf{2}$ & $\begin{array}{l}\text { Total cost of manual spreading (considering the labour charges as } \square 300 \\
\text { per day of } 8 \text { hour), } \square \text { /ha }\end{array}$ & 786 \\
\hline
\end{tabular}


Fig.1 Isometric view of farm yard manure spreader

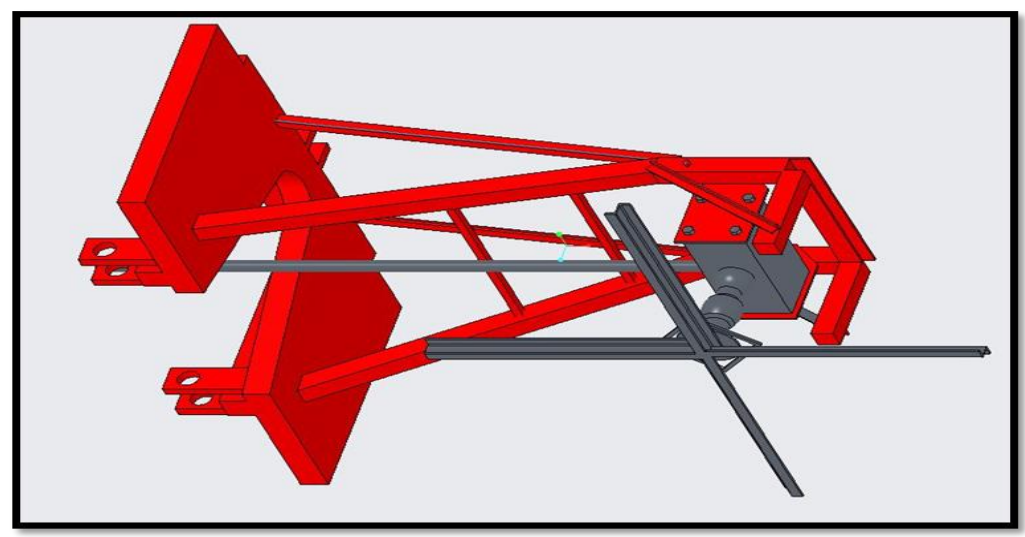

Fig.2 Schematic diagram of Farm Yard Manure Spreader

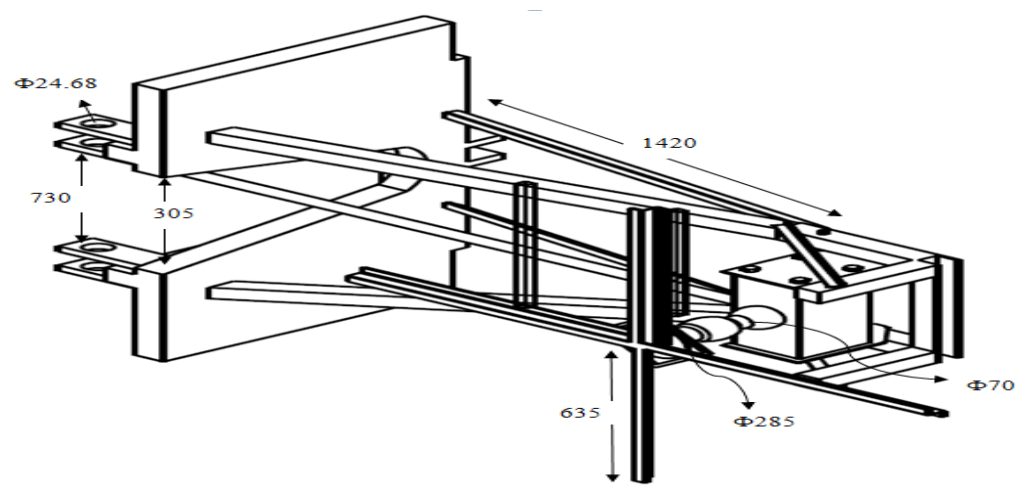

Fig.3 Developed farm yard manure spreader

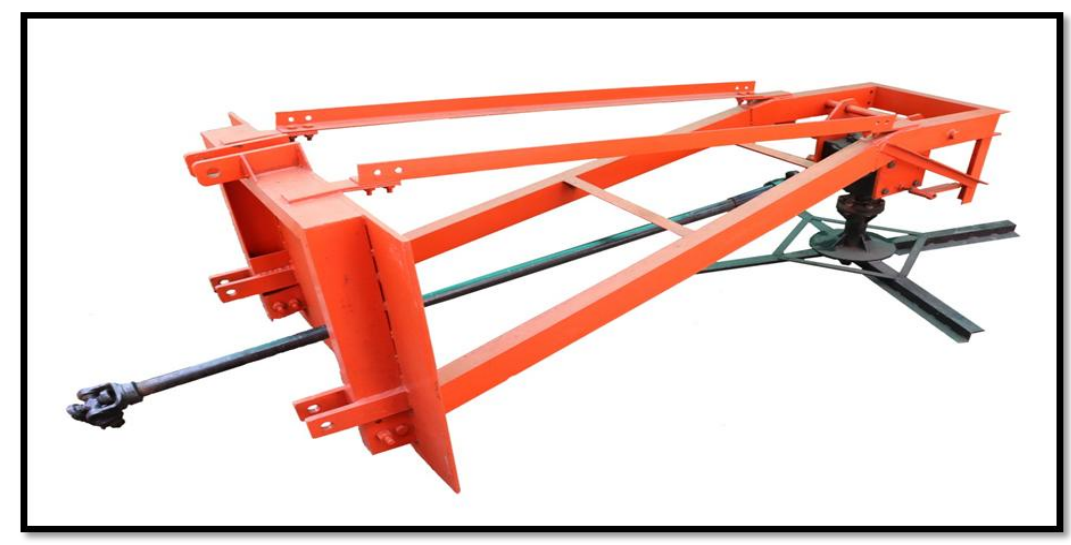

\section{Uniformity of spreaded FYM}

The uniformity of farm yard manure was calculated on basis of area covered with spreaded FYM material. In that process lime powder (white chuna) was used. Randomly selected samples measured and dividing values of that condition was observed. The value of uniformly spread was calculate in spreader $80 \%$ and manually $55 \%$. 


\section{Fuel consumption}

The fuel consumption for spreading was 2.11 $1 / \mathrm{h}$.

\section{Evaluation of economics}

\section{Time}

The total time of operation including time required for turning, repair and adjustment was measured. The operational time for developed spreader was 3.44 minutes and for manually spreading it was calculated 8.54 minute for 0.0504 ha area.

The economically comparison between manual and mechanical spreading methods have $59.61 \%$ reduction in time over manual spreading.

\section{Energy consumption}

It was observed that in developed machine energy consumption was $182.46 \mathrm{MJ} / \mathrm{ha}$ and for manually spreading it was $39.2 \mathrm{MJ} / \mathrm{ha}$.

\section{Cost of operation}

The economically comparison between manual and mechanical spreading methods to save $17.30 \%$ reduction in cost over manual spreading.

\section{References}

Anonymous. 2019. Agriculture in India. Available at http:// en.wikipedia.org/wiki/agriculture in India. Accessed on 21 November, 2019.

Ravindranath, N. H., Somashekar, H. I., Nagaraja M. S., Sudha P., Sangeetha, G., Bhattacharya, S. C. and Abdul Salam, P. 2005. Assessment of sustainable nonplantation biomass resources potential for energy in India, Biomass and Bioenergy. 29: 178-190.

Rahul Batta, Mahesh Kumar Narang, Rupinder Chandel. 2015. Field and economic studies of tractor operated manure Spreader with rear vertical rollers- a need based study for Organic farming approach in Indian agriculture. International Journal of Agricultural Science and Research (IJASR). 5 (6): 347-356.

Reddy, M. C. and Dronachari, M., 2014. "Physical and Frictional Properties of Manure at Various Depths in Compost Pit”, Journal of Academia and Industrial Research, 2(9): 503-506.

Singh, R. C. 2013. Development and Performance Testing of a Tractor Trailer cum farmyard Manure Spreader. Journal of Agricultural Engineering Research. 7(2).

\section{How to cite this article:}

Lalit Savaliya, T. D. Mehta, Ravi Kathiria and Ravikumar Hirpara. 2021. Development of Tractor Operated Farm Yard Manure Spreader. Int.J.Curr.Microbiol.App.Sci. 10(02): 469-475. doi: https://doi.org/10.20546/ijcmas.2021.1002.055 